Discussion Paper No. 792

\title{
AIRPORT PRIVATIZATION \\ AND INTERNATIONAL COMPETITION
}

\author{
Toshihiro Matsumura \\ Noriaki Matsushima
}

September 2010

The Institute of Social and Economic Research

Osaka University

6-1 Mihogaoka, Ibaraki, Osaka 567-0047, Japan 


\title{
Airport privatization and international competition*
}

\author{
Toshihiro Matsumura \\ Institute of Social Science, University of Tokyo \\ Noriaki Matsushima ${ }^{\dagger}$ \\ Institute of Social and Economic Research, Osaka University
}

September 11, 2010

\begin{abstract}
We provide a simple theoretical model to explain the mechanism whereby privatization of international airports can improve welfare. The model consists of a downstream (airline) duopoly with two inputs (landings at two airports) and two types of consumers. The airline companies compete internationally. Using the simple international duopoly model, we show that the outcome where both airports are privatized is always an equilibrium while that where no airport is privatized is another equilibrium only if the degree of product differentiation is large.
\end{abstract}

JEL classification: L33, L13, R48

Key words: Airline, Airport, Privatization, International competition, Vertical relations

* We would like to thank Masahide Daigo, Kojun Hamada, Toshio Matsuzawa, Kunio Miyashita, Keizo Mizuno, Se-il Mun, Takeshi Nakata, Naoko Nishimura, Hisashi Oi, Kenichi Shoji, Koji Takamiya, Takeshi Yamazaki, Muneki Yokomi, and seminar participants at Niigata University, Shinshu University, and the Japan Society of Transportation Economics for their helpful comments. The authors gratefully acknowledge financial support from Grant-in-Aid from the Japanese Ministry of Education, Science and Culture. Needless to say, we are responsible for any remaining errors.

$\dagger$ Corresponding author: Noriaki Matsushima, Institute of Social and Economic Research, Osaka University, Mihogaoka 6-1, Ibaraki, Osaka 567-0047, Japan. Phone: +81-6-6879-8571, Fax: +81-6-68798583, E-mail: nmatsush@iser.osaka-u.ac.jp 


\section{Introduction}

Following the example of the UK, many countries have moved - or are moving - towards privatization of some public airports. Research on airport privatization has been popular recently (Basso (2008), Basso and Zhang (2008), Zhang and Zhang (2003, 2006)). For instance, in their seminal paper on airport privatization, Zhang and Zhang (2003) raise the following question: can we expect that the profit-maximizing behavior of privatized, unregulated airports will lead to social welfare maximization, or is there a conflict between maximizing social welfare and maximizing profits? They incorporate the problem of congestion, capacity investment, and market power over landing charges into a privatization policy framework and compare the price decisions of privatized, unregulated airports with those of public airports that maximize social welfare. Although these studies of airport privatization provide interesting insights, they do not show situations in which privatization improves welfare; thus a welfare-maximizing government has no incentive to privatize airports.

In this paper, we present a model in which local welfare-maximizing governments have incentives to privatize airports and show why many countries have moved towards privatization of public airports. We consider a simple downstream (airline) duopoly with two inputs (landings at two airports). The model setting is as follows. ${ }^{1}$ There are two downstream firms (airlines) that supply final products to consumers (passengers). Each airline company procures two inputs for its final product. Each input is monopolistically supplied by an independent supplier. In the context of airline competition, the inputs are related to airports commonly used by the airline companies.

We consider the following three-stage game. First, each government independently decides whether to privatize its airport. The objective of a public airport is to maximize domestic welfare, while that of the private airport is to maximize its own profit. ${ }^{2}$ In the second stage, the airports independently set their airport charges. In the third stage, two

\footnotetext{
${ }^{1}$ We do not consider the problems of congestion and capacity at airports, although these are often discussed in the papers mentioned above. Our purpose is to show that privatization can be beneficial even though such negative effects, which might be mitigated by privatization, are absent.

2 This, in addition to the competition structure in the second and the third stages, follows the model assumption in Zhang and Zhang (2003).
} 
airlines face price competition and set their prices simultaneously.

We show that each government privatizes its airport so as to maximize its domestic social surplus in equilibrium. We also find that the governments may face a prisoners' dilemma situation, that is, commitments to nonprivatization policies may be mutually beneficial for the two countries.

The intuition behind the result is as follows. The strategic interaction between the airports is that of strategic substitution. That is, when an airport charge is high (low), the charge set by another airport becomes low (high). This is because a higher airport charge diminishes the demand for each airline, which is closely correlated to the derived demand for the other airport. Given the strategic interactions, we now consider the relation between the airport charges and the objectives of the airports. A national airport sets a lower airport charge than a privatized one because the national airport considers not only its own profit but also that of the domestic airline company and consumer welfare. When the other airport is foreign, this lower charge set by the national airport is the transfer from it to the other airport. This causes a welfare loss that can dominate the welfare gain for consumers and the profit of the domestic airline company. Because privatization of an airport is a commitment not to lower its airport charge, this can improve its domestic social surplus.

The remainder of the paper is organized as follows. Section 2 presents the model. Section 3 provides the main result. Finally, Section 4 concludes the paper.

\section{The model}

There are two downstream firms, $D_{1}$ and $D_{2}$, which supply final products to consumers. Each maximizes its own profit. The final products are differentiated. In the context of airline competition, the downstream firms are associated with airline companies.

Each downstream firm procures two inputs $(A$ and $B)$ for its final product. Inputs $A$ and $B$ are supplied by monopolistic common suppliers, $U_{i}(i=A, B)$. In the context of airline competition, the inputs are related to the use of airports. To produce a unit of final product, each downstream firm uses one unit of input $A$ and one of input $B$ :

$$
q_{i}=\min \left\{q_{i}^{A}, q_{i}^{B}\right\},
$$


where $q_{i}^{j}$ is the amount of input $j(j=A, B)$. That is, each downstream firm has Leontief production technology. Suppliers incur no marginal cost for a unit of input. Except for procurement costs, the production costs of the downstream firms are zero. We assume that the suppliers unilaterally set the input prices, $w_{A}$ and $w_{B}$, respectively. We also assume that the suppliers do not price discriminate. In this setting, per-unit cost of each downstream firm is given as

$$
c_{i}=w_{A}+w_{B}, \quad(i=1,2) .
$$

There are two consumer groups, $C_{A}$ and $C_{B}$, which differ in size. The size of group $A$ is $\lambda_{A}=1$ and that of group $B$ is $\lambda_{B}=\lambda(\leq 1)$. That is, the size of group $A$ is larger than or equal to that of group $B$. The total demand for firm $i$ 's product is given as $q_{i A}+\lambda q_{i B}$. Each consumer group $j$ has the inverse demand functions of the products, denoted by $(j=A, B)$

$$
p_{i j}=1-q_{i j}-\gamma q_{-i j}, \quad i,-i=1,2,(i \neq-i),
$$

where $q_{i j}$ is the amount of firm $i$ 's product and $\gamma$ is the degree of product differentiation $(\gamma \in(0,1))$. From the inverse demand functions, the demand functions are derived

$$
q_{i j}=\frac{1-\gamma-p_{i j}+\gamma p_{-i j}}{1-\gamma^{2}}, \quad i,-i=1,2,(i \neq-i) .
$$

When $\gamma=1$, the products are perfect substitutes; when $\gamma=0$, they are independent. In the context of airline competition, the two airlines compete on the same route between airports $A$ and $B$ because the two downstream firms use the common input suppliers $\left(U_{A}\right.$ and $\left.U_{B}\right)$. Therefore, it is reasonable that the products are substitutes.

The profit of downstream firm $i(i=1,2)$ is given as

$$
\pi_{D i}=\left(p_{i A}-\left(w_{A}+w_{B}\right)\right) q_{i A}+\left(p_{i B}-\left(w_{A}+w_{B}\right)\right) \lambda q_{i B}, \quad i=1,2 .
$$

The net consumer surplus in country $j(j=A, B)$ is given as $\left(\lambda_{A}=1\right.$ and $\left.\lambda_{B}=\lambda\right)$

$$
\begin{aligned}
C S_{j} & =\lambda_{j}\left(q_{1 j}+q_{2 j}-\frac{q_{1 j}^{2}+2 \gamma q_{1 j} q_{2 j}+q_{2 j}^{2}}{2}-p_{1 j} q_{1 j}-p_{2 j} q_{2 j}\right) \\
& =\lambda_{j}\left(\frac{2(1-\gamma)\left(1-p_{1 j}\right)\left(1-p_{2 j}\right)+\left(p_{1 j}-p_{2 j}\right)^{2}}{2\left(1-\gamma^{2}\right)}\right)=\lambda_{j}\left(\frac{q_{1 j}^{2}+2 \gamma q_{1 j} q_{2 j}+q_{2 j}^{2}}{2}\right) .
\end{aligned}
$$


The profit of upstream firm $i(i=A, B)$ is given as

$$
\pi_{U i}=w_{i}\left(q_{1 A}+q_{2 A}+\lambda\left(q_{1 B}+q_{2 B}\right)\right), \quad i=A, B .
$$

In the model, we assume that the nationalities of $D_{1}, U_{A}$, and $C_{A}\left(D_{2}, U_{B}, C_{B}\right)$ are common, and also assume that those of $D_{1}$ and $D_{2}$ differ. ${ }^{3}$ For instance, in the context of airline competition, $U_{A}$ is a domestic airport from the viewpoint of $D_{1}$ and $U_{B}$ is a foreign one. The market structure is summarized in Figure 1.

[Figure 1 here]

We consider two cases concerning the objective of each input supplier. One is that the objective of an input supplier is to maximize its own profit. The other is that the objective of an input supplier is to maximize its domestic social surplus. In the context of airline competition, the former relates to a privatized airport, and the latter to a nationalized airport. This specification is used in the literature of airport privatization (e.g., Zhang and Zhang (2003), Basso and Zhang (2007)). Because two suppliers exist, we must consider four cases concerning the objectives of the two suppliers: (1) Both suppliers are profit maximizers; (2) $U_{A}$ is a profit maximizer and $U_{B}$ is a domestic welfare maximizer; (3) $U_{B}$ is a profit maximizer and $U_{A}$ is a domestic welfare maximizer; (4) Both suppliers are domestic welfare maximizers. When $U_{i}$ is a profit maximizer, it maximizes $\pi_{U i}(i=A, B)$. When $U_{A}\left(U_{B}\right)$ is a domestic welfare maximizer, it maximizes $\pi_{U A}+C S_{A}+\pi_{D 1}\left(\pi_{U B}+C S_{B}+\pi_{D 2}\right)$.

The game proceeds as follows. First, each government simultaneously determines whether or not it privatizes its input supplier. Second, each common supplier simultaneously sets $w_{i}$ to maximize its objective, which is determined in the first period $(i=A, B)$. Third, given the wholesale prices $w_{A}$ and $w_{B}$, the downstream firms simultaneously set their prices at $p_{i}(i=1,2)$. We assume that the downstream firms cannot price discriminate between the consumer groups $A$ and $B$. That is, $p_{i A}=p_{i B}=p_{i}(i=1,2)$.

\section{Result}

We solve the game by backward induction.

\footnotetext{
${ }^{3}$ Of course, the nationalities of $U_{A}$ and $U_{B}\left(C_{A}\right.$ and $\left.C_{B}\right)$ are different.
} 


\subsection{The third stage}

We first consider the third-stage game. The objective function of downstream $i$ is:

$$
\begin{aligned}
\pi_{D i} & \equiv\left(p_{i}-w_{A}-w_{B}\right)\left(q_{i A}+\lambda q_{i B}\right) \\
& =\frac{\left(p_{i}-w_{A}-w_{B}\right)(1+\lambda)\left(1-\gamma-p_{i}+\gamma p_{-i}\right)}{1-\gamma^{2}}, \quad i=1,2, \quad i \neq-i .
\end{aligned}
$$

The first-order conditions lead to

$$
p_{i}=\frac{1-\gamma+w_{A}+w_{B}}{2-\gamma}, \quad \pi_{D i}=\frac{(1+\lambda)(1-\gamma)\left(1-w_{A}-w_{B}\right)^{2}}{(2-\gamma)^{2}(1+\gamma)}, \quad i=1,2, j \neq i .
$$

The domestic social surplus in country $A(B)$ is the sum of the consumer surplus in country $A(B)$ and the total profits of $D_{1}$ and $U_{A}\left(D_{2}\right.$ and $\left.U_{B}\right)$. The social surplus in country $j(j \in\{A, B\})$ is given as

$$
\begin{aligned}
S W_{j}=\frac{\lambda_{j}\left(1-w_{A}-w_{B}\right)^{2}}{(2-\gamma)^{2}(1+\gamma)} & \\
& +\frac{(1+\lambda)(1-\gamma)\left(1-w_{A}-w_{B}\right)^{2}}{(2-\gamma)^{2}(1+\gamma)}+\frac{2 w_{j}(1+\gamma)\left(1-w_{A}-w_{B}\right)}{(2-\gamma)(1+\gamma)},
\end{aligned}
$$

where $\lambda_{A}=1$ and $\lambda_{B}=\lambda$.

\subsection{The second stage}

There are four cases (subgames) that depend on the first-stage decisions of the governments: (1) Both suppliers are profit maximizers; (2) $U_{A}$ is a profit maximizer and $U_{B}$ is a domestic welfare maximizer; (3) $U_{B}$ is a profit maximizer and $U_{A}$ is a domestic welfare maximizer; (4) Both suppliers are domestic welfare maximizers.

Privatization of the suppliers, $U_{A}$ and $U_{B}$. We first consider the case in which the objective of the suppliers is to maximize their own profits. In other words, we consider the situation after privatization of the suppliers, $U_{A}$ and $U_{B}$.

The maximization problem of supplier $i$ is represented by

$$
\max _{w_{i}} w_{i}\left(q_{1 A}+q_{2 A}+\lambda\left(q_{1 B}+q_{2 B}\right)\right) .
$$

Let the superscript ' $\mathrm{PP}$ ' denote the equilibrium value when the suppliers are private firms. The maximization problems represented in (3) lead to

$$
w_{i}\left(w_{-i}\right)=\frac{1-w_{-i}}{2} \quad(i=1,2,-i \neq i) \quad \rightarrow \quad w_{A}^{P P}=w_{B}^{P P}=\frac{1}{3} .
$$


This result is summarized in the following lemma:

Lemma 1 The strategic interaction between the suppliers is that of strategic substitution. When the suppliers are profit maximizers, the equilibrium wholesale price in the subgame is $w_{A}^{P P}=w_{B}^{P P}=1 / 3$.

The reaction function in (4) means that the strategic interaction between the suppliers is strategic substitution. When a supplier sets its wholesale price at a higher level, the total quantity demanded by the downstream firms shrinks. Given the shrunken demand caused by the high price, the other supplier is forced to set a lower price (Cournot (1838) and Sonnenschein (1968)). Note that this situation exists irrespective of the suppliers' objectives (profit or welfare maximization).

The profits of the firms are given as

$$
\pi_{U i}^{P P}=\frac{2(1+\lambda)}{9(2-\gamma)(1+\gamma)}, \quad \pi_{D j}^{P P}=\frac{(1-\gamma)(1+\lambda)}{9(2-\gamma)^{2}(1+\gamma)}, \quad i=A, B ; j=1,2 .
$$

The domestic social surplus in each country is given as

$$
S W_{A}^{P P}=\frac{6+5 \lambda-3(1+\lambda) \gamma}{9(2-\gamma)^{2}(1+\gamma)}, \quad S W_{B}^{P P}=\frac{5+6 \lambda-3(1+\lambda) \gamma}{9(2-\gamma)^{2}(1+\gamma)} .
$$

Only $U_{A}$ is privatized Second, we consider the case in which the objective of $U_{A}$ $\left(U_{B}\right)$ is to maximize its own profit (its domestic social surplus). In other words, we consider the situation in which only $U_{A}$ is privatized.

The maximization problem of supplier $i$ is represented by

$$
\begin{aligned}
\max _{w_{A}} & w_{A}\left(q_{1 A}+q_{2 A}+\lambda\left(q_{1 B}+q_{2 B}\right)\right), \\
\max _{w_{B}} & w_{B}\left(q_{1 A}+q_{2 A}+\lambda\left(q_{1 B}+q_{2 B}\right)\right) \\
& \quad+\left(p_{2}-w_{A}-w_{B}\right)\left(q_{2 A}+\lambda q_{2 B}\right)+\frac{\lambda\left(q_{1 B}^{2}+2 \gamma q_{1 B} q_{2 B}+q_{2 B}^{2}\right)}{2} .
\end{aligned}
$$

Let the superscript ' $\mathrm{PN}$ ' denote the equilibrium value when only $U_{A}$ is a private firm. The maximization problems represented in (6) lead to

$$
\begin{gathered}
w_{A}\left(w_{B}\right)=\frac{1-w_{B}}{2}, \quad w_{B}\left(w_{A}\right)=\frac{1-w_{A}}{3+2 \lambda-(1+\lambda) \gamma}, \\
\rightarrow \quad w_{A}^{P N}=\frac{(2-\gamma)(1+\lambda)}{5+4 \lambda-2(1+\lambda) \gamma}, \quad w_{B}^{P N}=\frac{1}{5+4 \lambda-2(1+\lambda) \gamma} .
\end{gathered}
$$

We easily find that $w_{A}^{P N}>w_{B}^{P N}$. This is summarized in the following lemma: 
Lemma 2 When only $U_{A}$ is privatized, it sets a higher wholesale price than $U_{B}$. That is, $w_{A}^{P N}>w_{B}^{P N}$.

The reason is as follows. The domestic welfare maximizer $\left(U_{B}\right)$ takes into account the domestic consumer surplus and the domestic downstream firm's profit as well as its own profit. Because a lower wholesale price helps both consumers and the domestic firm, the domestic welfare maximizer $\left(U_{B}\right)$ sets a lower price than the profit maximizer $\left(U_{A}\right)$.

The profits of the firms are given as

$$
\begin{aligned}
& \pi_{U A}^{P N}=\frac{2(2-\gamma)(1+\lambda)^{3}}{(1+\gamma)(5+4 \lambda-2(1+\lambda) \gamma)^{2}}, \quad \pi_{U B}^{P N}=\frac{2(1+\lambda)^{2}}{(1+\gamma)(5+4 \lambda-2(1+\lambda) \gamma)^{2}} \\
& \pi_{D A}^{P N}=\pi_{D B}^{P N}=\frac{(1-\gamma)(1+\lambda)^{3}}{(1+\gamma)(5+4 \lambda-2(1+\lambda) \gamma)^{2}}
\end{aligned}
$$

The domestic social surplus in each country is given by

$$
S W_{A}^{P N}=\frac{(6+5 \lambda-3(1+\lambda) \gamma)(1+\lambda)^{2}}{(1+\gamma)(5+4 \lambda-2(1+\lambda) \gamma)^{2}}, \quad S W_{B}^{P N}=\frac{(3+2 \lambda-(1+\lambda) \gamma)(1+\lambda)^{2}}{(1+\gamma)(5+4 \lambda-2(1+\lambda) \gamma)^{2}} .
$$

Only $U_{B}$ is privatized Third, we consider the case in which the objective of $U_{B}\left(U_{A}\right)$ is to maximize its own profit (its domestic social surplus). In other words, we consider the situation in which only $U_{B}$ is privatized.

The maximization problem of supplier $i$ is represented by

$$
\begin{aligned}
\max _{w_{A}} & w_{A}\left(q_{1 A}+q_{2 A}+\lambda\left(q_{1 B}+q_{2 B}\right)\right) \\
& +\left(p_{1}-w_{A}-w_{B}\right)\left(q_{1 A}+\lambda q_{1 B}\right)+\frac{q_{1 A}^{2}+2 \gamma q_{1 A} q_{2 A}+q_{2 A}^{2}}{2}, \\
& \max _{w_{B}} w_{B}\left(q_{1 A}+q_{2 A}+\lambda\left(q_{1 B}+q_{2 B}\right)\right) .
\end{aligned}
$$

Let the superscript 'NP' denote the equilibrium value when only $U_{B}$ is a private firm. The maximization problems represented in (8) lead to

$$
w_{A}^{N P}=\frac{\lambda}{4+5 \lambda-2(1+\lambda) \gamma}, \quad w_{B}^{N P}=\frac{(2-\gamma)(1+\lambda)}{4+5 \lambda-2(1+\lambda) \gamma} .
$$

We easily find that $w_{A}^{N P}<w_{B}^{N P}$. This is summarized in the following lemma:

Lemma 3 When only $U_{B}$ is privatized, it sets a higher wholesale price than $U_{A}$. That is, $w_{A}^{N P}<w_{B}^{N P}$. 
The reason is similar to that in the previous case.

The profits of the firms are given by

$$
\begin{aligned}
& \pi_{U A}^{N P}=\frac{2 \lambda(1+\lambda)^{2}}{(1+\gamma)(4+5 \lambda-2(1+\lambda) \gamma)^{2}}, \quad \pi_{U B}^{P N}=\frac{2(2-\gamma)(1+\lambda)^{3}}{(1+\gamma)(4+5 \lambda-2(1+\lambda) \gamma)^{2}}, \\
& \pi_{D A}^{N P}=\pi_{D B}^{P N}=\frac{(1-\gamma)(1+\lambda)^{3}}{(1+\gamma)(4+5 \lambda-2(1+\lambda) \gamma)^{2}} .
\end{aligned}
$$

The domestic social surplus in each country is given by

$$
S W_{A}^{N P}=\frac{(2+3 \lambda-(1+\lambda) \gamma)(1+\lambda)^{2}}{(1+\gamma)(4+5 \lambda-2(1+\lambda) \gamma)^{2}}, \quad S W_{B}^{N P}=\frac{(5+6 \lambda-3(1+\lambda) \gamma)(1+\lambda)^{2}}{(1+\gamma)(4+5 \lambda-2(1+\lambda) \gamma)^{2}} .
$$

No supplier is privatized Finally, we consider the case in which the objective of the suppliers is to maximize their own social surplus. In other words, we consider the situation in which no supplier is privatized.

The maximization problem of supplier $i$ is represented by

$$
\begin{aligned}
\max _{w_{A}} & w_{A}\left(q_{1 A}+q_{2 A}+\lambda\left(q_{1 B}+q_{2 B}\right)\right) \\
& +\left(p_{1}-w_{A}-w_{B}\right)\left(q_{1 A}+\lambda q_{1 B}\right)+\frac{q_{1 A}^{2}+2 \gamma q_{1 A} q_{2 A}+q_{2 A}^{2}}{2}, \\
\max _{w_{B}} & w_{B}\left(q_{1 A}+q_{2 A}+\lambda\left(q_{1 B}+q_{2 B}\right)\right) \\
& +\left(p_{2}-w_{A}-w_{B}\right)\left(q_{2 A}+\lambda q_{2 B}\right)+\frac{\lambda\left(q_{1 B}^{2}+2 \gamma q_{1 B} q_{2 B}+q_{2 B}^{2}\right)}{2} .
\end{aligned}
$$

Let the superscript 'NN' denote the equilibrium value when no supplier is privatized. The maximization problems represented in (10) and (11) leads to

$$
w_{A}^{N N}=\frac{\lambda}{(3-\gamma)(1+\lambda)}, \quad w_{B}^{N N}=\frac{1}{(3-\gamma)(1+\lambda)} .
$$

The result for the difference between $w_{A}^{N N}$ and $w_{B}^{N N}$ is summarized in the following lemma:

Lemma 4 When the suppliers are domestic surplus maximizers, $w_{A}^{N N} \leq w_{B}^{N N}$, and the equality holds only if $\lambda=1$. That is, the wholesale price in the country with a larger number of consumers is smaller than in the one with a smaller number of consumers.

The nationalized supplier considers consumer welfare and the domestic downstream firm's profit as well as its own profit. Because consumer welfare is more important in the country with a larger number of consumers (country $A$ ), $w_{A}^{N N}<w_{B}^{N N}$ in equilibrium. 
The profits of the firms are given by

$$
\begin{aligned}
& \pi_{U A}^{N N}=\frac{2 \lambda}{(3-\gamma)^{2}(1+\lambda)}, \quad \pi_{U B}^{N N}=\frac{2}{(3-\gamma)^{2}(1+\lambda)}, \\
& \pi_{D A}^{N N}=\pi_{D B}^{N N}=\frac{(1-\gamma)(1+\lambda)}{(3-\gamma)^{2}(1+\gamma)} .
\end{aligned}
$$

The domestic social surplus in each country is given by

$$
S W_{A}^{N N}=\frac{2+3 \lambda-(1+\lambda) \gamma}{(3-\gamma)^{2}(1+\gamma)}, \quad S W_{B}^{N N}=\frac{3+2 \lambda-(1+\lambda) \gamma}{(3-\gamma)^{2}(1+\gamma)} .
$$

\subsection{Privatization policy: The first stage}

We now discuss decisions regarding privatization; that is, the first stage of the game is discussed. The first stage is represented by the following $2 \times 2$ matrix.

\begin{tabular}{|l|c|c|c|}
\hline A/B & \multicolumn{2}{|c|}{$P$} & \multicolumn{2}{c|}{$N$} \\
\hline \multirow{2}{*}{$P$} & \multicolumn{2}{|c|}{$S W_{B}^{P P}$ in (5) } & \multicolumn{2}{|c|}{$S W_{B}^{P N}$ in (7) } \\
& \multicolumn{2}{|c|}{$S W_{A}^{P P}$ in (5) } & $S W_{A}^{P N}$ in (7) \\
\hline \multirow{2}{*}{$N$} & \multicolumn{2}{|c|}{$S W_{B}^{N P}$ in (9) } & \multicolumn{2}{|c|}{$S W_{B}^{N N}$ in (13) } \\
& $S W_{A}^{N P}$ in (9) & $S W_{A}^{N N}$ in (13) \\
\hline
\end{tabular}

From the payoff matrix, we have the following proposition.

Proposition 1 For any exogenous parameter, $(P, P)$ is an equilibrium outcome. If the following inequalities are satisfied, $(N, N)$ is an equilibrium outcome:

$$
\lambda \geq \frac{-\left(1-3 \gamma+\gamma^{2}\right)+\sqrt{7-8 \gamma+2 \gamma^{2}}}{(3-\gamma)(1-\gamma)} \text { and } \gamma \leq \frac{3-\sqrt{6}}{2} \simeq 0.275
$$

Neither $(P, N)$ nor $(N, P)$ appears in equilibrium.

Proof See the Appendix.

The following figure indicates the area in which $(N, N)$ can be an equilibrium outcome.

[Figure 2 here]

Proposition 1 states that the outcome where both governments privatize their own suppliers (henceforth, we call this PP equilibrium) is always an equilibrium, while that where no government privatizes its own supplier (henceforth, we call this $N N$ equilibrium) can 
fail to be an equilibrium. Figure 2 indicates that the area for the existence of $N N$ equilibrium is small. Thus, we believe that $P P$ equilibrium is more likely to occur than $N N$ equilibrium. ${ }^{4}$

We now explain the intuition behind the proposition. As explained above, because the strategic interaction between the suppliers is strategic substitution, lowering $w_{i}$ leads to higher $w_{-i}(i=1,2, i \neq-i)$. Because the supplier $-i$ is a foreign firm, this price shift caused by a lower $w_{i}$ is a transfer from the domestic to the foreign supplier. This causes a welfare loss from the viewpoint of domestic welfare in country $i$. In any case, this welfare loss is important for each country. Therefore, each government decides to privatize its own supplier when it anticipates that the other supplier is privatized.

In this setting, the degree of competitiveness $(\gamma)$ also affects the welfare property concerning the objectives of the suppliers. When $\gamma$ is large (competition between the downstream firms is severe), the negative effect of double marginalization is small because downstream firms cannot exert their market power. The strategic interaction between the suppliers is relatively important for each country. Moreover, the difference between the number of consumers in the countries is also important. The supplier in the country with a larger number of consumers sets its wholesale price at a lower level (Lemma 4). This causes a transfer from this country to the foreign country. To reduce such a transfer, the supplier in the country with a larger number of consumers tends to be privatized.

We now briefly discuss the relation between the levels of social welfare in two cases: (1) both upstream suppliers are privatized, $(P, P)$; $(2)$ no upstream supplier is privatized, $(N, N)$. When both upstream suppliers are privatized, the sum of wholesale prices $w_{A}+$ $w_{B}$ is higher than that in the case where no upstream supplier is privatized; that is, $w_{A}^{P P}+w_{B}^{P P}>w_{A}^{N N}+w_{B}^{N N}$. Although the higher wholesale prices in the privatized case reduce 'global' welfare, this negative effect of privatization is not always applied to the social surplus in the large country (country $A$ ). After a simple calculation, we have the following proposition:

\footnotetext{
${ }^{4}$ Even when two equilibriums exist, we can show that $P P$ equilibrium risk dominates that of $N N$ equilibrium, so the former is more robust. For the concept of risk dominance, see Harsanyi and Selten (1988).
} 
Proposition $2 S W_{B}^{P P}<S W_{B}^{N N}$ for all $\lambda$ and $\gamma \cdot S W_{A}^{P P}>S W_{A}^{N N}$ if and only if

$$
\lambda<\frac{3(2-\gamma)\left(-3+6 \gamma-2 \gamma^{2}\right)}{(3-\gamma)\left(21-22 \gamma+6 \gamma^{2}\right)} .
$$

Figure 3 indicates the area in which the inequality in Proposition 2 is satisfied.

[Figure 3 here]

From the figure, we can see that privatization of the two upstream suppliers improves social welfare in the large country when downstream competition is severe and the heterogeneity of the consumer sizes is significant.

As shown in Lemma $4, w_{A}^{N N}<w_{B}^{N N} . w_{B}^{N N}$ in (12) is increasing in $\gamma$ and decreasing in $\lambda$. That is, when $\gamma$ is large and $\lambda$ is small, the rent shifting from country $A$ to $B$ is significant. We now briefly explain the reason for this. When $\gamma$ is large (downstream competition is severe), the profits of the downstream firms are small. This implies that consumer welfare and the upstream profits are more important than the downstream profits. Therefore, each nationalized upstream supplier tends to set a higher price, which harms the downstream firms. A higher wholesale price harms consumer welfare but increases its upstream profit. Because the former negative effect is relatively important for the large country, $A, w_{A}$ tends to be lower than $w_{B}$. When $\lambda$ is small (the difference between the consumer sizes is large), the difference between $w_{B}^{N N}$ and $w_{A}^{N N}$ is large. This is because the nationalized supplier in country $A$ takes into account its (relatively) large consumer size when it sets $w_{A}$. Moreover, the strategic substitutability of the upstream prices exacerbates the difference between the wholesale prices. Therefore, when $\gamma$ is large and $\lambda$ is small, privatization of the two upstream suppliers improves social welfare in the large country, that is, $S W_{A}^{P P}>S W_{A}^{N N}$.

\section{Concluding remarks}

We provide a simple theoretical model to explain the mechanism by which a government privatizes its international airport to maximize domestic welfare. The model consists of a simple downstream (airline) duopoly with two inputs (two airports). Using the simple international duopoly model, we show that privatization of the airport can improve the domestic social surplus. A lower price set by an airport leads to higher prices set by the 
other airport. Because the other airport is a foreign one, this price shift is the transfer from the domestic to the foreign one. This causes a welfare loss from the viewpoint of domestic welfare.

In this paper, we do not consider congestion problems, which are often discussed in the literature on airline competition (Brueckner (2002, 2009), Yuen et al. (2008), Zhang and Zhang $(2006,2010))$. Considering this problem will make the analysis richer, and this is a consideration for future research. 


\section{Appendix}

Proof of Proposition 1: $\quad S W_{A}^{P P}-S W_{A}^{N P}$ and $S W_{B}^{P P}-S W_{B}^{P N}$ are given as

$$
\begin{aligned}
& S W_{A}^{P P}-S W_{A}^{N P} \\
= & \frac{(2-\gamma+(1-\gamma) \lambda)\left(3(2-\gamma)^{2}+2(2-\gamma)(7-3 \gamma) \lambda+\left(17-14 \gamma+3 \gamma^{2}\right) \lambda^{2}\right)}{9(2-\gamma)^{2}(1+\gamma)(2(2-\gamma)+(5-2 \gamma) \lambda)^{2}}>0, \\
& S W_{B}^{P P}-S W_{B}^{P N} \\
= & \frac{(1-\gamma+(2-\gamma) \lambda)\left(\left(17-14 \gamma+3 \gamma^{2}\right)+2(2-\gamma)(7-3 \gamma) \lambda+3(2-\gamma)^{2} \lambda^{2}\right)}{9(2-\gamma)^{2}(1+\gamma)(5-2 \gamma+2(2-\gamma) \lambda)^{2}}>0 .
\end{aligned}
$$

$(P, P)$ is an equilibrium outcome for all of the parameters, $\gamma \in(0,1)$ and $\lambda \in(0,1]$. These inequalities imply that neither $(N, P)$ nor $(P, N)$ is an equilibrium outcome. $S W_{A}^{N N}-$ $S W_{A}^{P N}$ and $S W_{B}^{N N}-S W_{B}^{N P}$ are given as

$$
\begin{aligned}
& S W_{A}^{N N}-S W_{A}^{P N} \\
= & \frac{(2-\gamma+(1-\gamma) \lambda)\left(-\left(2+2 \gamma-\gamma^{2}\right)+2\left(1-3 \gamma+\gamma^{2}\right) \lambda+(3-\gamma)(1-\gamma) \lambda^{2}\right)}{(3-\gamma)^{2}(1+\gamma)((5-2 \gamma)+2(2-\gamma) \lambda)^{2}} \\
& S W_{B}^{N N}-S W_{B}^{N P} \\
= & \frac{(1-\gamma+(2-\gamma) \lambda)\left((3-\gamma)(1-\gamma)+2\left(1-3 \gamma+\gamma^{2}\right) \lambda-\left(2+2 \gamma-\gamma^{2}\right) \lambda^{2}\right)}{(3-\gamma)^{2}(1+\gamma)(2(2-\gamma)+(5-2 \gamma) \lambda)^{2}}
\end{aligned}
$$

$S W_{A}^{N N}-S W_{A}^{P N} \geq 0\left(S W_{B}^{N N}-S W_{B}^{N P} \geq 0\right)$ if and only if

$$
\begin{aligned}
& S W_{A}^{N N}-S W_{A}^{P N} \geq 0 \Leftrightarrow \lambda \geq \frac{-\left(1-3 \gamma+\gamma^{2}\right)+\sqrt{7-8 \gamma+2 \gamma^{2}}}{(3-\gamma)(1-\gamma)}, \\
& S W_{B}^{N N}-S W_{B}^{N P} \geq 0 \Leftrightarrow \lambda \leq \frac{\left(1-3 \gamma+\gamma^{2}\right)+\sqrt{7-8 \gamma+2 \gamma^{2}}}{2+2 \gamma-\gamma^{2}} .
\end{aligned}
$$

After some calculus, we find that both inequalities are satisfied if and only if $\gamma \leq(3-$ $\sqrt{6}) / 2$. We also easily show that $\left(1-3 \gamma+\gamma^{2}+\sqrt{7-8 \gamma+2 \gamma^{2}}\right) /\left(2+2 \gamma-\gamma^{2}\right)$ is larger than 1 if $\gamma \leq(3-\sqrt{6}) / 2$. Therefore, the condition under which $(N, N)$ is an equilibrium outcome is given by

$$
\lambda \geq \frac{-\left(1-3 \gamma+\gamma^{2}\right)+\sqrt{7-8 \gamma+2 \gamma^{2}}}{(3-\gamma)(1-\gamma)} \text { and } \gamma \leq \frac{3-\sqrt{6}}{2} \simeq 0.275
$$

This calculus leads to Proposition 1.

Q.E.D. 


\section{References}

[1] Basso, Leonardo J., 2008. "Airport deregulation: Effects on pricing and capacity," International Journal of Industrial Organization, 26(4), 1015-1031.

[2] Basso, Leonardo J. And Anming Zhang, 2008. "Sequential peak-load pricing in a vertical setting: the case of airports and airlines," Canadian Journal of Economics, 41(3), 1087-1119.

[3] Brueckner, JAn K., 2002. "Airport congestion when carriers have market power," American Economic Review, 92(5), 1357-1375.

[4] Brueckner, Jan K., 2009. "Price vs. quantity-based approaches to airport congestion management," Journal of Public Economics, 93(5,6), 681-690.

[5] Brueckner, Jan K. And Kurt Van Dender, 2008. "Atomistic congestion tolls at concentrated airports? Seeking a unified view in the internalization debate," Journal of Urban Economics, 64(2), 288-295.

[6] Cournot, Augustin, 1838. Researches into the Mathematical Principles of the Theory of Wealth, (Macmillan, New York); English translation, N. Bacon, 1897.

[7] Harsanyi, John C. and Reinhard Selten, 1988. A General Theory of Equilibrium Selection in Games. MIT Press, Cambridge, MA.

[8] Pels, Eric and Erik T. Verhoef, 2004. "The economics of airport congestion pricing," Journal of Urban Economics, 55(2), 257-277.

[9] Sonnenschein, Hugo, 1968. "The dual of duopoly is complementary monopoly: or, two of Cournot's theories are one," Journal of Political Economy, 76(2), 316-318.

[10] Yuen, Andrew, Leonardo J. Basso, and Anming Zhang, 2008. "Effects of gateway congestion pricing on optimal road pricing and hinterland," Journal of Transport Economics and Policy, 42(3), 495-526.

[11] Zhang, Anming And Yimin Zhang, 2003. "Airport charges and capacity expansion: effects of concessions and privatization," Journal of Urban Economics, 53(1), 54-75. 
[12] Zhang, Anming and Yimin Zhang, 2006. "Airport capacity and congestion when carriers have market power," Journal of Urban Economics, 60(2), 229-247.

[13] Zhang, Anming And Yimin Zhang, 2010. "Airport capacity and congestion pricing with both aeronautical and commercial operations," Transportation Research Part B: Methodological, 44(3), 404-413. 


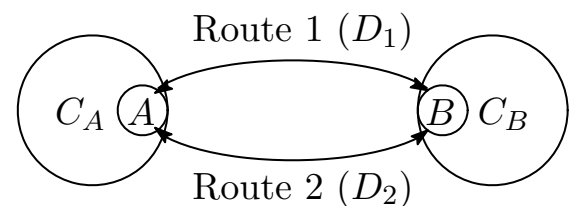

Market structure

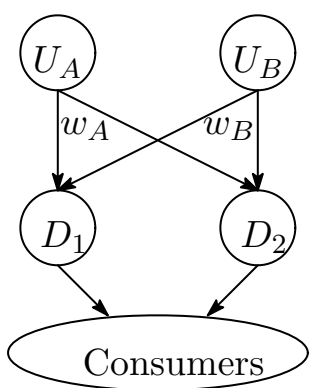

Vertical structure in this market.

Figure 1: The market structure

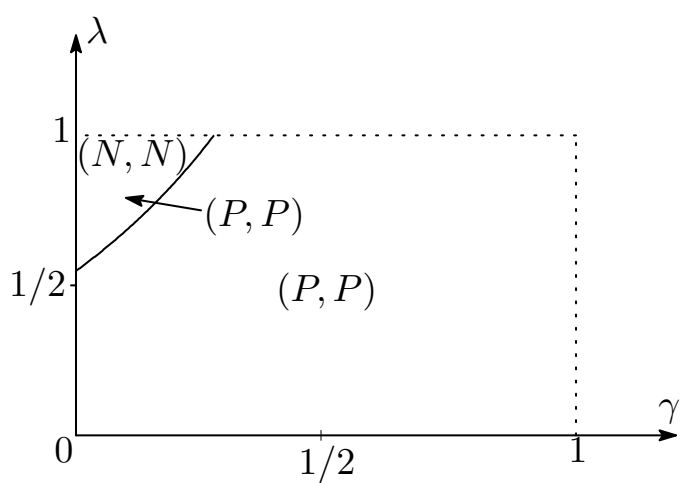

Figure 2: The condition that $(N, N)$ is an equilibrium outcome.

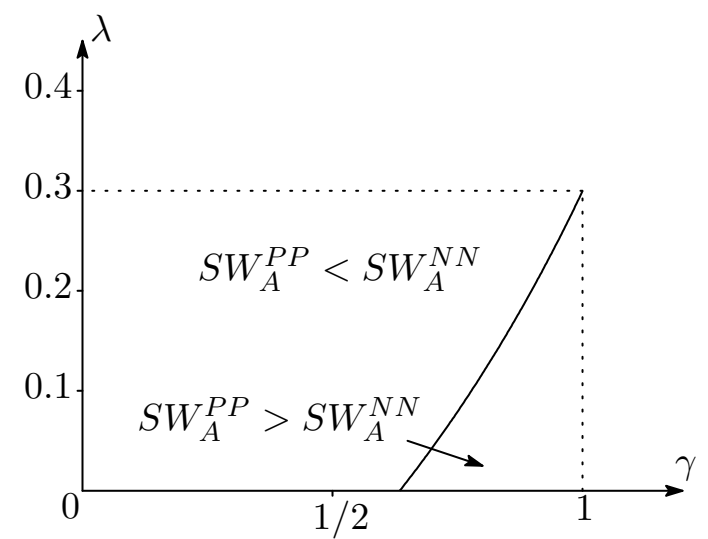

Figure 3: The condition that $S W_{A}^{P P}>S W_{A}^{N N}$. 